\title{
CORRESPONDENCE
}

To the Editor:

\section{BOXING SHOULD BE MODIFIED}

Dear Sir,

At one time, deviant behaviour in boxers was attributed to their aggressive personalities rather than to repetitive minor brain damage, but this view is changing, following work by such as $\mathrm{H}$. S. Martland and $\mathrm{N}$. Corsellis. I have reliable information of a Sri Lankan boxer who tried to murder his wife and is now certified insane. Floyd Patterson was admitted to hospital concussed after his defeat by Sonny Liston; Benny Kid Paraet died in coma after a knock-out by Emil Griffiths; Carmino Vingo had to retire with permanent brain damage after defeat by Rocky Marciano. Partly as a result of these severe injuries in PROFESSIONAL boxing, the very different AMATEUR sport is becoming much less popular all over the world, and is far less popular in Sri Lankan schools. Boxing, however, is still a most popular sport from the spectators' viewpoint, and is a sport that attracts a great deal of money throughout most of the world. It is one of the few ways open to boys from a poor background, especially in the U.S.A., Cuba and parts of Africa with a large population of African descent, to find a way of making a successful career. It would therefore be tragic if this type of activity were to cease.

The continuation of boxing as a sport can only be justified if the destructive effects of blows to the brain can be avoided, and it is time that the game be modified so that participants can benefit from a valuable form of physical activity without paying the price of cerebral contusion, with possible cell degeneration, tentorial and falx tears, and post-traumatic automatism that may sometimes be found in older professional fighters. The use of padded headguards, more padding in gloves, stricter refereeing and better medical supervision would all help. It is possible that future developments in electronics will enable automatic point counting (and foul counting!) devices to be produced, as in fencing, to reduce some of the subjective scoring that has to be made by the referee and judges. If some of these measures could be put into operation, it should reduce risk, and yet allow the continuance of this most popular and lucrative sport.

Yours faithfully,

B. L. A. Hemachandra

\section{University of Technology}

\section{DEPARTMENT OF HUMAN SCIENCES}

9 June, 1975.

Dear Sir,

Having read with very great interest the Proceedings of the Symposium on the future of Sports Medicine in the United Kingdom (B.A.S.M. 1975, 9, 25-45) may we be permitted to make a contribution.

In the concept of Sports Medicine the emphasis has been placed upon the Medical aspect with little emphasis being attached to the aspect of Sport. The trend of thought appears to be directed towards the development of medical people who have a particular interest in sport. Whilst we agree that this channel should be explored fully, nevertheless we feel that possibly an equally important and, as yet, not adequately developed approach has to be made through recruitment of people who are sports orientated but who have a particular interest in medicine. Although this approach 
would perhaps appear a little limited in terms of application in the near future, it nevertheless appears to go well with the future developments of Physical Education, as we see them.

The importance and value of a medically qualified, sports orientated person must never be underestimated. His expertise, particularly regarding recovery from injury, will always be recognised as irreplaceable, and every effort must be made to increase the number of people in this category. On the other hand there is, as yet, an untapped source of potential help in the world of P.E. particularly in terms of the recognition of injuries and diagnosis, and even more importantly, in terms of prevention of injuries.

Physical Education appears to be developing along two distinct paths. One path is concerned with the understanding of "What makes sport necessary?" and incorporates the fundamental ideas on "the most effective way of achieving what we believe". From this has developed the second theme of Recreational Administration and this includes the provision of opportunities for achieving our objectives. From this understanding, therefore, Physical Education has a firm scientific foundation and should always have a strong scientific bias. Similarly, Physical Education in schools should always be viewed as an extension of the Science Department and perhaps in terms of a recognisable application to the students, it is arguably the only Science in the school.

In this respect the Physical Education teacher of the future is, by necessity, going to need to be more qualified scientifically and, more specifically, will need to be more medically orientated in his outlook. It is only a matter of time before we begin to question the medical qualifications of the Physical Education teacher who, with a Certificate of Education, is licenced to instruct and guide in the development and maintenance of the human body. How far removed is this from practising medicine?

Misnomers appeared to be another theme of the Symposium and perhaps it is relevant to mention the apparent misnomer of the National Health Service. The majority of people only go to the hospital or to see their G.P. when they are ill, and therefore the National Health Service ought, perhaps, to be called the National III-Health Service. This is not meant to upset the medical profession but is merely an attempt to illustrate that very little appears to be done in terms of the preventive aspect of medicine and it serves to emphasize that there is a great potential within the Physical Education world in this regard. The Physical Education teacher's situation is primed for the mantle of preventive medicine. Where expertise is required in terms of recovery from injury then, by all means, allow the specialist training of the medic to be utilized but where the emphasis is upon preventive medicine and recognition of injuries then allow the Physical Education teacher to play his obvious role.

Yours faithfully,

Keith M. Bagnall

Edward M. Winter

Ever since its inception the medical members of BASM have only too well been aware of the part played in Sports Medicine by those in related professions. To achieve its proper status in medicine, nationally and internationally, the first essential is the attainment of excellence in the clinical aspect, with recognised courses of study leading to a high minimum standard of competence. The very important role to be played by those in other professions in this multi-disciplinary organisation of BASM will follow, once the primary aim of good clinical work has been established. 